\title{
THE IMPACT OF SAUDIS’ ATTITUDES TOWARDS GRAFFITI
}

\author{
Mansour Dhafer Al Qarni' \\ Universiti Kebangsaan Malaysia, \\ Faculty of Social Sciences and Humanities, \\ School of Language Studies and Linguistics Department, \\ Bangi, Malaysia. Tel: 966-504733032 \\ (Email: abdjafer202@gmail.com) \\ Abdullah Hassan Al Qarni \\ Universiti Kebangsaan Malaysia, \\ Faculty of Social Sciences and Humanities, \\ School of Language Studies and Linguistics Department, \\ Bangi, Malaysia.
}

Accepted date: 05-03-2019

Published date:11-07-2019

To cite this document: Al Qarni, M. D., \& Al Qarni, A. H. (2019). The Impact of Saudis' Attitudes towards Graffiti. International Journal of Humanities, Philosophy, and Language, 2(6), 51-62.

DOI: $10.35631 / \mathrm{ijhpl} .26005$

\begin{abstract}
Inscription is a common and a widely used literary technique in communication. This technique is used to deliver an underlying message indirectly. The intended meaning of the words used in inscription form is different from its actual meaning. This literary device is used actively in the Western World and there have been many studies on this area conducted by several researchers. Though inscription on the restrooms is also used by citizens of Saudi Arabia in their communication. Thus, toilet graffiti is a unique window into the relationship between gender, language, and social context. Whereas, the other public places have less painting, drawing and relationship between both genders. Therefore, we would like to propose this paper in Saudi's graffiti. Also, the importance of how women and men communicate, no comparable situation in which both men and women write graffiti has ever been studied. This study sought to set a new benchmark: focusing not only on at the topic of graffiti but also at the language style in which inscriptions were written, and not in male and female toilets but also in an analogous mixed-gender context in different places. Strong gender differences are found for topic in the findings. Female's Graffiti tends to be politer, love, relationship, less assertive and interactive, whereas those from the male graffiti indicate more argumentative and negative behavior with racial discrimination. One of the most important results is indicated that both genders are used graffiti in toilet stall in order to express their attitude, psychological case whether positively or negatively. They want to keep on themselves away from their people sights. Gender differences in language style are subtler but generally consistent with those found in other contexts. Gendered language is mitigated in the mixedgender context. Topics in the mixed-gender context are a composite of the topics found in the men's and women graffiti but also included the only sexist remarks in the data.
\end{abstract}


Keywords: Graffiti; Gendered Communications; Anonymous Communications; Thematic Analysis, Attitude and Genders

\section{Introduction}

Language is the main tool of communication and transmission of beliefs, thoughts, arts and sciences. It helps people to understand each other, so it is considered as a social activity. Graffiti, as a part of the society, depends clearly on the language to reach their ends. There is a close relationship between language and the activities of graffiti. Language is a means of shaping policies in words via inscriptions of texts or graffiti writings which reinforce ideologies in the public to attain specific objectives.

Graffiti, in this case plays an essential role in communication and information transmission, since it is a sort of scribbling and inscription. Graffiti is a means of "the combination of statements and drawings" (Walker Red ,1935:96). In addition, Graffiti "refers to any kind of crude or casual drawings, slogan, inscription, or writing scratched or scribbled on buildings, walls, fences, or other public surfaces" (D'Angelo, 1976). The purpose of graffiti is to convey a message of a text via inscription. So, conducting studies on transmitting the ideas, thoughts, attitudes, languages, and inscriptions sheds more light on the issue of graffiti manipulation.

In the Arab World, graffiti is one of the most important tools that are used to spread thoughts, ideas, attitudes, styles, and behaviors or morals to the local societies indirectly in order to convince people with specific ideologies, unique behaviors, and specific information. The geographical location of Saudi Arabia, however, shows the importance of the country at various levels including the birthplace of Islam, the largest storage of petroleum in the world and the international transportations. In this capacity, graffiti plays a crucial role in the Saudi society. We can see different ways of graffiti in various places including restrooms, toilets ,homeless places, universities, malls, street walls, cars and t-shirts

The current study will focus only on graffiti in different situations in local communities. The study will try to answer the following questions : 1 . What are the roles of the variations of graffiti among Saudis people ? 2. What are the reasons behind the instances of variations of graffiti in different places? 3. Why do Saudi teenagers write on the walls, tables, desks , doors, bridges and homeless places, wall of cemetery and scripture on the stones more than girls? 4. What are the bahaviour consequences of graffiti in these places?

\section{Statement of the Problem}

After surveying the related literature, the researchers noticed that there are many studies conducted to investigate the graffiti to reveal the reasons behind this phenomenon. Not many studies look at the role of graffiti in Saudi Arabia. What are the reasons behind the phenomenon?

Nonetheless, Martyna (2007) points out the critiques of social phenomena named as 'commitment' via two types of contemplations involving narrative and graffiti. He talks about graffiti in media and academic literature. He finds that graffiti are commonly illustrated as vilified terms separated from the norm of society or consolidated by the modern art of discourse. He supports his study by the Boje's concept of 'antenarrative' to challenge the dichotomous depictions of graffiti, particularly in relation to the notion of commitment". 
In the same vein, a study conducted to address the same issue by Lakeoff et ( 1975 ) compares women's speeches and men's speeches. They find that women's speeches are more polite and less assertive than men's speeches. They add that women always utilize question tags, hypercorrect grammar, certain adjectives and expletive statements while men imply their viewpoint directly and a few of men use lovely words including pretty, cute and nice. In addition, women's language concentrates on personal traits whereas men pay attention to aggressive behaviors and refuse interpersonal issues by contesting.

Although there are several studies examining graffiti in different parts of the world, this phenomenon has not been extensively studied in Saudi Arabia. Therefore, the current study will try to bridge the gap by using the content analysis and thematic analysis approach to analyze the variations of instances of graffiti and to identify the reasons behind it in Saudi Arabia. To achieve the objectives of the study, the researchers will deal with graffiti in different situations .

\section{Objectives of the Study}

The study will address the following objectives:

1. To identify the reasons behind the instances of variations of graffiti in Saudi Arabia

2. To classify the professional skills behind the widespread of graffiti in Saudi Arabia

3- To categorize the types of graffiti in terms of color, sex and age .

4- To analyze the ideological variations of graffiti in Saudi Arabia

\section{Significance of the Study}

During the history of the graffiti studies, many studies have been conducted to investigate graffiti, but a limited number of studies have dealt with the issue of variation in instances of behavior in graffiti and the reasons behind it. Therefore, the present study will try to shed more light on the phenomenon of graffiti in gender at different situations .

Second, it seeks to identify the reasons that lead to such variation. The main goal of this study is to provide a new understanding to the role of Saudi graffiti. Another aspect of the significance of the present study lies in attempting to reveal how this manipulated graffiti affect the opinion of their readers .

\section{Literature Review}

The following sections review related literatures in graffiti. Few studies have been conducted on graffiti. The two researchers attempt to review a number of studies dealing with graffiti. The thematic analysis approach will be used to expose texts, discursive, sociological factors and others. The focus is on studies of graffiti in general, and the toilet stalls, school's walls and streets and other places in Saudi Arabia, in particular.

\section{Thematic Analysis Approach}

According to Wikipedia ( 2016) "Thematic analysis is one of the most common forms of analysis in qualitative research". This approach intends to investigate the patterns of themes via collecting data. Such themes are expressed across data sets. This approach is provided by Chang, Fisher and Meredith (2012). In this respect, the two researchers will apply the Thematic Analysis Approach in the current study. Since this approach concentrates on the varieties of data sets from different restrooms. Thus, the study consists of many themes involving alliances, love, tagging, hetrosexual affairs, competition, philosophy, economy and political issues. All 
of these themes will be related to the contexts, texts, political issue conversations, phrases, proverbs, poems and drawing on the restrooms.

\section{Saudi Arabia}

Saudi Arabia is a huge country. It covers more than 2000 kilometers from the north edge to the south border. In this wide area, habits and traditional customs are not the same in the Kingdom of Saudi Arabia(KSA). The thematic issue of Saudis' understanding refers to how men and women communicate with each other by using graffiti. Graffiti, therefore, expresses a specific interaction between diverse types of genders comprising women to men, women to other women, and men to men. They express their feelings and privacy in particular places. The toilet graffiti, in this case, plays a significant role in the interaction between males and females in different domains. Public toilets and other places such streets are more salient than specific or private areas for both genders.

Notwithstanding, the local language is Modern Standard Arabic (MSA) and there are many vernacular accents in different places of Saudi Arabia. In addition, there is a pidgin language which is coming on the surface by the interaction between Saudi people and non-native speakers including Pakistani, Indian, and Bangladeshi expatriates and others. This new language creates a weak and low standard level of the Arabic language. It is a useless language in the local society. Saudi people use this dialect with non-natives in order to make communication with them easily. In fact, it is a very dangerous dialect which will affect new generations.

In contrast, the Arabic language is used extensively in various fields of the Saudi peoples' life including institutions, centers, public and private schools, universities, and even in interactive settings where non-Arabic speakers communicate. In all of these situations, we can see various kinds of graffiti. Different people in Saudi Arabia seem to use graffiti widely and easily . In fact, there are no rules to prevent the widespread of graffiti in various places. Many people express their attitudes, thoughts , beliefs and their arts on the wall by graffiti . In fact, there is no limited age of graffiti's writing on the building, restroom, bridges and slogans in Saudi Arabia . Thus, it is widespread and remarkable in different places where anyone can draw or scribble .

In this capacity, all of these settings lead the two researchers to explore graffiti in Saudi Arabia .This kind of art is widespread in the country. It has two pragmatic aspects, positive and negative. The positive side of graffiti is clarified across inscription writings like AlDaryah and Madin Salah. Whereas, the negative one is exhibited on the toilets' walls and doors and other buildings. Many bad words are written there whether directly or indirectly containing sexual orientation, harassment, insults ,offense and racial discrimination .

\section{Studies Related to Graffiti}

In this state of affairs, graffiti is a worldwide phenomenon that expresses deep feelings of communication and interaction between people indirectly. This word derives from an Italian word which is so-called "Graffitio." It means an art of scribbling and inscription. Graffiti is "the combination of statements and drawings" (Allen Walker Red 1935:96). A few studies have been conducted on graffiti in different situations .The social contexts of graffiti in restrooms is a means of communication between genders. It expresses the direction and attitudes of interaction thoughts and behaviors in various dimensions. Graffiti represents scratching and scribbling on walls, restrooms, slogans, buildings and stalls. 
However, graffiti "refers to any kind of crude or casual drawings, slogan, inscription, or writing scratched or scribbled on buildings, walls, fences, or other public surfaces" (D'Angelo, 1976,p: 102). In the human history of culture, D'Angelo(1976) and Fisher, M. L. \& Radtke, S (2014) stated that .: Bathroom Graffiti Human Ethology Bulletin - Proc. of the IV ISHE Summer Institute (2014): 68-8169

"...the word graffiti...was originally used by archaeologists to describe the kind of casual writings and drawings found on the walls of ancient buildings in Pompeii, as well as in Roman

catacombs and on ancient Egyptian monuments. These graffiti were scratched on plaster and

limestone surfaces with sharp instruments or written on walls with charcoal and red chalk by

schoolboys, common citizens, and travelers" (p. 102).

In the previous eras, graffiti was encountered in the caves by drawing some inscriptions. Reisner (1971) stated that the first examples occurred in cave drawings of deer and bison in Europe which led to graffiti expressed via Egyptians. He mentioned that "Mayan, Aztec and Incan hieroglyphs, to Latin phrases, then expressed as drawings and etchings in Christian churches, monasteries and dungeons of Medieval Europe, through to European wall graffiti". Interestingly, the sociological issue of graffiti appeared particularly in the 1970s. To support this point of view, Ley and Cybriwsky (1974) investigated autographical graffiti in Philadelphia produced by gang members as territorial markers. More recently, Brown (1995) revealed how her students discovered Hungarian graffiti. The students believed that graffiti would be humorous, political, and philosophical rather than sexual references, profanity, references to Western popular music.

Additionally, some studies on graffiti primarily displayed that many inscriptions of graffiti are done by males. They utilized graffiti in an argumentative debate by dominating the discourse (e.g., Kinsey, Pomeroy, Martin, \& Gebhard, 1953; Otta, Tannen 1990 ,1993; Schreer \& Strichartz, 1997; Sechrest \& Flores, 1969) In contrast, females in liberal universities used more graffiti than male .( Stocker, Dutcher, Hargrove, and Cook (1972).

Political issues figure out many big differences between the two genders in political graffiti. Some of studies indicate that females always use graffiti in writing of some political topics ( Schreer \& Strichartz, 1997) On the other hands, males display political topics of graffiti ( e.g., Loewenstine, Ponticos, \& Paludi, 1982; Otta et al., 1996) To support this point of view , a study conducted in North America about graffiti in high schools. The results showed that $80 \%$ of the graffiti were written by females Ahmed, 1981; Wales \& Brewer, 1976; but see Peretti, Carter, \& McClinton, 1977) In the same respect, Otta( 1993 ) found that around $15.4 \%$ of male graffiti about specific political topic were written by males while $14.9 \%$ were written by females. He concluded that both genders were the same with respect to writing about political issues.

\section{Language And Style Of Graffiti In Different Places}

One of the most popular factors in graffiti inscription is the style of the language. The language is a means of communication. It expresses the emotional feelings of human beings. These feelings are represented in words, contexts, phrases, statements and body language in interaction whether directly or indirectly. Thus, the language of graffiti varies, in the case of, men and women. Moreover, there are many divergences between males and females 
in their graffiti. The content of the language between them has two arguments. These arguments have divided scholars and researchers towards Graffiti into two groups. The first trend refers to researchers such as (Kutakoff 1972, Loewenstine et al. 1982, Cole 1991, Fitzpatric, Mulac and Dindia, 1995 ) who declare that women introduce bawdiness, less references to bisexuality, masculinity, sexual interaction, masturbation and gonorrhea infection. In addition, social interaction, personal problems, advice, romantic issues and morality are frequently spread in women's writings. Female graffiti regardless of their viewpoints comprises advisory, impersonal relationship, happiness traits, enjoyable life, tag questions and language with high standard.

Another study is done by James (1995) which focuses on the perspective of communication between male and female inscriptions. He seeks a remedy for methodological failings and relates them to the social identity. He finds big differences between male and female writings. He concludes his study by saying that graffiti in female are more polite and interactive whereas in male they refer to negative trends and argumentative concepts. In addition, he adds that gender language is more mitigated in the mixed-gender context.

Furthermore, the socioeconomic status of students is indicated in toilets graffiti. Female students show two levels of socioeconomics. The lowest socioeconomic factor involves toilet romantic writing while the highest level of the socioeconomic background declares less romantic and more erotic writing (Wales and Brewer 1976:115-123) To support this issue, toilet wall inscription by males in the United States deviates from the socioeconomic status. This state of affairs is manifested as a higher form status in professional schools like medicine , law, and dentistry. The comparison between these schools in relation to heterosexual messages and homosexual inscription reveals that the heterosexual messages have more affection than homosexual inscription written by fourth year students (Sechrest and Olson 1971:62-71).

Additionally, Al Rousan (2011) finds difference between Jordanian graffiti in relation to the typographical features in the text messages. He classifies his study into four typographical features including punctuation, letter, number homophones, phonetic spelling and emotion issues. He analyzes more than 2050 text messages utilizing face -to -face communication and computer mediated communication. He reveals that there are gender differences among young Jordanian undergraduates in the text messages of typographical features .

Many researchers around the world analyze and discuss the domains of graffiti in deep detail. The first researcher who observed the widespread of scribbling in toilets was Allen Walker Red ( 1953 ). He noted that the stalls of graffiti on the walls of toilets were widely spread. He claimed that graffiti is the way of drawing combined with statements. After that era, Dundes (1966) struggled a new word of graffiti that was so-called * Latrinalia '. However, many researchers like Reisner (1971) believe that that graffiti was an old art and old culture referring to many years in the past. Reisner stated that the graffiti on the wall of toilets expressed a specific art via people voicing.

Notwithstanding, there are many studies that found graffiti written by females are more sexual than male graffiti (Bates \& Martin, 1980), whereas more by males than females as in the works of (Schreer\&Strichartz, 1997), but no difference between the two genders (Otta et al., 1996) In addition to this state of affairs, Ahmed (1981) reported that male graffiti writing is more erotic inscription whereas females inscriptions are more romantic writing. 
Nonetheless, Bruner and Kelso (1980) claimed that men's graffiti often boasted about their sexual conquests, sexual frequency, and sexual prowess in text. On the other hand, graffiti was more relationship-focused and more interactive, with a string of responses and thoughtful replies.

The time of Graffiti started from the Egyptian era. Old Egyptians used graffiti in their mummies. It was also found in the Greek temples and the Roman ruins especially in the city of Pompeii (C.F Fraser 258, Malhorn and Romig 30). In that time, they used graffiti as an art, but today it is used differently. This art has two sides, positive and negative. It seems to be positive when it is used as an art whereas it is negative when it becomes a tool of oppression and vandalism. To conclude, toilet graffiti is a unique window to analyze social contexts and the relationship between genders (Raisul Islam 2001).

Furthermore, there are two schools in graffiti inscriptions. The first team indicates graffiti as a means of communication for both genders. Female graffiti entails "advice to the loveforlorn and [on] existential issues about life, marriage, and happiness" whereas, male graffiti is more racially degradation or prejudiced (Loeenstine et al ., 1982; Bruner \&Kelso, 1981; Otta, 1993; Schreer \& Strichartz, 1997; Stocker et al., 1972) In contrast, Graffiti for both genders is indicated as more homophobic, more insulting, offensive and aggressive (Stocker et al., 1972; Solomon \& Yager, 1975; Bates \& Martin, 1980; Bruner\&Kelso, 1981; Otta, 1993)

\section{Methodology}

This chapter concentrates on the population of the study, the sample, and the main purpose of this study. Moreover, it will discuss in details data collection, validity and reliability of the study and data analysis. Thus, the current study will combine both qualitative and quantitative research approaches. The two forms of data are integrated in the design through merging, connecting or embedding the data. However, as this area of study has never been explored, it will therefore be more of an exploratory nature than a quantitative one .

\section{Research Design}

Both research designs can have equal emphasis or one may be more dominant than the other. As mentioned above, the design of this research will be exploratory. The researchers will be reviewing data available from researchers who have conducted studies close in nature to the study that the researchers will be carrying out. They will also use primary data collection tools to get in-depth and valuable insights into this area.

\section{Sampling}

The two researchers will use purposeful sampling in order to select the most appropriate information of individuals. Thus, the population of this study will be Saudi people. A sample comprising 120 males and 90 females will be selected from different people's levels of education specializing in various disciplines including linguistics, philosophy, education, literature, health, economic, sociology and psychology.

\section{Research Instrument}

To carry out this study, the researchers will devise a questionnaire of 40 items of different types such as dichotomous questions, open ended questions, Likert questions, and rating scale questions. Therefore, the researchers will divide and categorize data into three sections. The first section typifies the background information about participants. The second one clarifies the positive and negative sides of Graffiti in Saudi Arabia. The last element attempts to 
investigate the domains behind the widespread of graffiti in the local society .This variety of questions is necessary for the purpose of the study.

\section{Procedures}

The researchers will use the following procedures in order to achieve the objectives of the current research.

$\checkmark$ Questionnaire - a questionnaire will be designed by the researchers and then will be given to respondents. The researchers will ask them to fill them out. Once filled, the researchers will take the questionnaire back and get the subjects' responses for analysis.

$\checkmark$ Group Discussions - The researchers will meet a group of local people and ask them about the reasons behind the instances of variations of graffiti .

$\checkmark$ Observation - The researchers will conduct interviews with a few participants by utilizing face-to-face communication individually .

\section{Data Collection}

Conversation analysis will be one of the methods of data collection. Questionnaire also will be used. Other methods include focus groups and in-depth interviews with subjects. Personal information of the subjects will be kept confidential, only the research findings will be used.

The data collection methods will include both unstructured and semi-structured techniques. In order to achieve the objectives of the present study, the researchers will develop a five-point scale questionnaire consisting of 40 items. These items deal with only the varieties of graffiti in restrooms and are intended to reveal the reasons behind the instances of variations of graffiti . Thus, two experts in the field of linguistics will measure the validity of the instrument.

In addition, the first part of this instrument seeks personal information about respondents' age, gender, and level of education. The second section asks the respondents to express their opinion of graffiti as follows: strongly agree, agree , neutral , disagree and strongly disagree. The questionnaire will be distributed in Arabic to avoid any difficulty in understanding the items in English. Then, the researchers will translate the items from Arabic to English. One of the researchers will distribute the questionnaire to the respondents. It will take at least one month to give the participants the questionnaire and to get it back.

\section{Validity And Reliability Of The Study Instrument}

To construct its validity, the questionnaire was given to a jury of two experts in linguistics who maintained that it had content validity. Reliability was established by the split-half method. The questionnaire was divided into two halves given to a sample of twenty respondents to answer them. The correlation between the scores given to their answers was then computed. The correlation was 0.80 ; the researchers, thus, concluded that the questionnaire is reliable.

\section{Data Analysis}

The contexts, texts, phrases of graffiti will be analyzed via thematic analysis approach . Such themes will be pointed out. The meaning of the different themes will also be categorized thematically. It will be illustrated as follows :

\section{SPSS Package}

Data collected from both unstructured and semi-structured means which include group discussions, interviews and a questionnaire will be analyzed properly and thoroughly. The data 
will be analyzed statistically using the SPSS package. The researchers will employ the following statistics: means, standard deviation, percentages and frequencies. The respondents' responses will be divided into two groups. Those who will get $60 \%$ or above out of the total of the participants' responses will mark as holding a positive attitude. However, a point of less than $60 \%$ will be taken as a negative attitude toward the aspects of graffiti dimensions in Saudi Arabia.

\section{Thematic Analysis Approach}

Content Analysis is detailed systematically by examining the particular of contents in order to identify patterns themes. The current researchers will use a thematic analysis approach to achieve some of the study's objectives. This approach is provided by Chang, Fisher and Meredith (2012). The data analysis will be carried out in two methods named as inductive and deductive approaches. The former indicates that theme is strongly related to the data whereas the latter covers less descriptive and focusing on one or two specific aspects. However, the researchers will categorize these themes into many patterns such as love ,tagging, alliance ,degradation (derogation) heterosexuality and insults . After analyzing data, the researchers will utilize the percentage or the frequency to obtain whether significant differences exist relevant to research questions .

\section{Results and Discussions}

Graffiti is an artistic theme which plays a significant roles in peoples' behaviors, socioeconomic, attitudes and emotional issues. In Saudi Arabia, as a case study, graffiti is developed in various cities such as Riyadh, Jeddah and Dammam. We can see various , inscription and paintings styles from street artists all over the places there. We can find graffiti in restrooms stalls, streets bridges, schools' walls, and other places. In addition, the government decorates streets' wall by some beautiful pictures. Other than that the local people of Saudi Arabia are very pleased welcome due to all the visitors which presents an art of expressions of their attitudes to foreigners. In this respect, young, old, male and female people around the country express their feelings and behaviors towards others as a social representations.

Saudi Arabia is Islamic country . It has the most sacred places in the world involving Makkah and Al Maddinah. All the people there $100 \%$ are Muslims. There is no religion competes with Islam. This style of Islam leads the local people to guide themselves to the right ways . As a matter of fact, we can find the majority of graffiti in Saudi Arabia is less than the nearest countries or around the world. The most important reason behind this issue is related to the deep of faith and the sociality of the local people. However, the language that is used in Saudi Arabia is Arabic. Most of the graffiti that is utilized in the local communities is Arabic language. We also find some scripture and slogan by other languages such as English.

The findings display positive attitudes towards Saudis in terms of graffiti who becomes a professional artist in paintings, scriptures and calligraphy. Such this attitudes of writings on walls do occurs in graffiti. The majority of the respondents of this attitudes is around $25 \%$ comparing with the negative attitudes. On the other hand, we can find polite, romantic style in communication between both genders in restrooms rather than other places. The frequency of the participants includes $86 \%$ avoiding political, social and sports styles which covers $14 \%$ of frequency . 
Writing is the most popular factor is used in graffiti rather than scripture and paintings. Such this issue refers to the easiness way of writing. The wide spread of color in graffiti whether in painting or writing is red, black and blue colors. The majority of the frequency that is using famous colors is $88 \%$ comparing with other different colors. The lowest percentage is covered $12 \%$ of the respondents .

According to the gender of graffiti, we can find females section are more romantic, polite , relational, soft style, beautiful painting and less assertive than men's speeches. The lowest frequency of graffiti is $22 \%$ whereas the highest is $78 \%$. The findings also show the graffiti in terms of age considering to the highest frequency which is related to ages from 12 to 16 ( teenagers ) with percentages $60 \%$. In other words , $10 \%$ of frequency refers to less than 12 years-old whereas we can find ages from 16- 20 with percentage includes $18 \%$. From 20 years-old to above have more than $11 \%$ of frequency. We can conclude this paper by saying that the highest positive attitudes of Saudis towards graffiti refers to females' speech and writing. The second positive behavior betokens to avoid offense, insults, less assertive in both genders because they are Muslims. The third positive issue is linked to professional skills of artist in painting, happiness and laughs characters. On the other hands, the most negative attitudes towards graffiti in Saudi Arabia is referred to racial discrimination, tagging questions, derogation, and aggressive behaviors whether between two genders or the same sex. In addition to this clarification, all the people who are using graffiti in restrooms, under bridges, homeless places and places away from watching have some psychological problem, frustration issue, isolations, disappointments, hopelessness, sadness, unhappiness. Such people like these are not be able to express their feelings, attitudes and behaviors rather than utilizing this graffiti in various places .

\section{References and Bibliography}

Ahmed, S. M. S. (1981). Graffiti of Canadian high school students. Psychological Reports,49, 559-562.

Bates, J. A., \& Martin, M. (1980). The thematic content of graffiti as a nonreactive indicator of male and female attitudes. The Journal of Sex Research, 16, 300-315.

Bruner, E. M.,\&Kelso, J.P. (1981). Gender differences in graffiti:A semiotic perspective. In S. Montague\& W. Arens (Eds.), The American dimension (pp. 139-156). Sherman Oaks, CA: Alfred.

Brown, J. C. (1995). The writing on the wall: The messages in Hungarian graffiti. Journal of PopularCulture, 29(2), 115-118.

Buser, M. M., \& Ferreira, F. (1980). Models and frequency and content of graffiti. Perceptual and Motor Skills, 51, 582.

Buss, D. M. (1991). Do women have evolved preferences for men with resources? A reply to Smuts.Ethology and Sociobiology, 12(5), 401-408.

Buss, D. M., \& Schmitt, D. P. (1993). Sexual strategies theory: An evolutionary perspective on human mating. Psychological Review, 100(2), 204-232.

Chang, R., Fisher, M., \& Meredith, T. (2012). Evolutionary perspectives on what women paint.Journal of Social, Evolutionary, and Cultural Psychology, 6(4), 442-452.

Cox, A. \& Fisher, M. (2009). The Texas billionaire's pregnant bride: An evolution interpretation of romance fiction titles. Journal of Social, Evolutionary, and Cultural Psychology, 3, 386-401.

Dindia, K., \& Allen, M. (1992). Sex differences in self-disclosure: A meta-analysis. Psychological Bulletin, 112, 106-124. 
D’Angelo, F. J. (1976). Fools' names and fools' faces are always seen in public places: A study of graffiti. The Journal of Popular Culture, 10(1), 102-109.

DeBacker, C., Nelissen, M., \& Fisher, M. (2007). Let's talk about sex: A study on the recall of gossip about potential mates and sexual rivals. Sex Roles, 56, 781-791

Fisher, M. L. \& Radtke, S.: Bathroom Graffiti Human Ethology Bulletin - Proc. of the IV ISHE Summer Institute (2014): 68-8180

Fisher, M. (2013). Women's intrasexual competition. In M. Fisher, J. Garcia, \& R. Chang (Eds.), Evolution's Empress: Darwinian perspectives on the nature of women (pp. 1942). New York: Oxford University Press.

Fisher, M. \& Cox, A. (2011). Four strategies used during intrasexual competition for mates. Personal Relationships, 18, 20-38.

Fisher, M. L. \& Radtke, S.: Bathroom Graffiti Human Ethology Bulletin - Proc. of the IV ISHE Summer Institute (2014): 68-8181

Fitzpatrick, M. A., Mulac, A., \& Dindia, K. (1995). Gender-preferential language use in spouse and stranger interaction. Journal of Language and Social Psychology, 14, 18 - 39.

James, B., \& Saville-Smith, K. (1994). Gender, culture and power: Challenging New Zealand's gendered culture (2nd ed.).Auckland,NewZealand:Oxford University Press.

Kinsey, A. C., Pomeroy, W. B., Martin, C. E., \& Gebhardt, P. H. (1953). Sexual behavior in the human female. Philadelphia, PA: W. B. Saunders.

Kuhle, B., \& Radtke, S. (2013). Born both ways: The alloparenting hypothesis for sexual fluidity in women. Evolutionary Psychology, 11, 304-323.

Lakoff, R. T. (1975). Language and women's place. New York: Harper and Row.

Ley, D., \& Cybriwsky, R. (1974). Urban graffiti as territorial markers. Annals of the Association of American Geographers, 64(4), 491-505.

Lindsey, D. G., \& Kearns, R. A. (1994). The writings on the wall: Graffiti, territory and urban space in Auckland. New Zealand Geographer, 50(2), 7-13.

Little, R., \& Sheble, M. (1987). Graffiti vandalism: Frequency and context difference between the sexes. American Journal of Criminal Justice, 11, 217-226.

Loewenstine, H.V., Ponticos,G.D.,\& Paludi, M. A. (1982). Sex differences in graffiti as a communication style. Journal of Social Psychology, 117, 307-308. Green / GENDER AND GRAFFITI 295

Otta, E. (1993). Graffiti in the1990s: Astudy of inscriptions on restroomwalls.Journal of Social Psychology, 133, 589-590.

Otta, E., Santana, P. R., Lafraia, L. M., Hoshino, R. L., Teixeira, R. P., \& Vallochi, S. L. (1996). Musa latrinalis: Gender differences in restroom graffiti. Psychological Reports, 78, 871-880.

Reisner, R. (1971). Graffiti: Two thousand years of wall writing. Cowles Book Company.

Sanborn, J. (2011). Tagged: The history of graffiti writing. New York: Lulu Press.

Sechrest, L., \& Flores, L. (1969). Homosexuality in the United States and the Philippines: The handwriting on the wall. Journal of Social Psychology, 79, 3-12

Schrest, L., \& Olsen, A. K. (1971). Graffiti in four types of institutions of higher education. The Journal of Sex Research, 7(1), 62-71.

Schreer,G. E.,\&Strichartz, J. M. (1997). Private restroom graffiti:An analysis of controversial social issues on two college campuses. Psychological Reports, 81, 1067-1074.

Teixeira, R. P., Otta, E., \& Siqueira, J. O. (2003). Between the public and the private: Sex differences in restroom graffiti from Latin and Anglo-saxon countries. Universidade de Sao Paulo, Working Paper number 03/007. Retrieved May 27, 2014 from http://www.ead.fea.usp.br/wpapers/2003/03-007.pdf 
Trivers, R. L. (1972). Parental investment and sexual selection. In B. Campbell (Ed.), Sexual selection and the descent of man 1871-1971 (pp. 136-179). Chicago: Aldine Publishing 